\title{
Justifying your public relations program
}

\author{
By Maureen Pastine
}

Director, Central University Libraries

Southern Methodist University

\section{A paper presented at the Midwinter Meeting of the ACRL Discussion Group on Public Relations in Academic Libraries.}

ublic relations means making the library visible. It is making the public aware of services, programs, operations, and activities, internal and external. A major purpose is to gain the support of the public. Through effective public relations programs, libraries can improve and enhance operations and services and better meet needs and demands.

Every task done and every encounter made with the public helps to determine the positive and negative images held by library clientele or potential library users. Thus, it is important to determine and design effective PR roles to create and maintain a positive public image and gain widespread support for the libraries.

\section{Ideas for PR purposes}

PR ideas can be found in any library journal, any library newsletter, or any library in-house publication. Our literature is replete with excellent PR ideas, successes and failures. The major problem is that there is more on programmatic ideas than on costs, and other resources involved, and whether a particular service/program was cost effective, cost beneficial, a financial success, or a financial failure. We need to consider how PR affects funding available for priority services and activities.
Librarians are often risk takers, creative, innovative, enthusiastic, motivated-but we do not often take the time necessary to plan adequately for priority services and evaluate them. We need to do so, and to report on those aspects, as well, in our published literature.

Some of the best sources for ideas can be found in The Bottom Line: A Financial Magazine for Librarians. Much of what is found here can be transposed to any library operation, service, program, sponsored event, or activity because there is a focus on planning, budgeting, and evaluating the results. Library Administration and Management is also quite useful. FOLUSA has also published many helpful guides on fundraising. Friends organizations' newsletters often report on the most successful fundraising done by their libraries. Unfortunately, a majority of these do not provide adequate information on the fiscal costs after staff/ volunteer time are figured in. They are good on planning aspects though, and creative use of volunteer time. The September 1985 issue of College and Research Libraries has an excellent article by Vicki Ford on "The State of PR in Academic Libraries," and there are some good tips on "PR for Libraries" in the January 1989 issue of American Libraries. There are three articles in the June 15, 1985, issue of Library Journal that are helpful. 


\section{Justification for PR: Success}

The major reason for conducting an active $\mathrm{PR}$ program is effectiveness in meeting user needs and demonstrating success through broad-based support. Julie Catalano, in an article, "The Eyes of Texas Are upon It: Trinity University," (Wilson Library Bulletin, January 1988, pp. 47-50) states, "In an area where logic dictates that libraries should be an indisputable priority, namely colleges and universities, academic institutions everywhere have a lengthy list of programs and possibilities competing for the same limited funds, with administrators and trustees often choosing sides for pet projects. .." She continues that "Unlike the schools, colleges, and departments, libraries do not have enrollment, graduates, or alumni. They offer no grades or degrees and, thus, have no specific constituency, yet everyone should be their constituency."

In order to build a first-rate library PR program, Catalano writes, it is essential to establish the fact that "the heart of any truly outstanding academic institution is its library." It is easy to gain lip service on this from administrators, faculty, legislators, and others. The difficulty is gaining and retaining the visibility and credibility to keep the library at the top of the university's priority list. That takes assertiveness and involvement in every aspect of university affairs, including instruction, curricular reform, and other academic issues. It means vying for committee assignments. It means playing an active role in campus and community affairs. And, it means involving those communities in library planning, gaining library support, and getting others to work for the libraries. It almost always means provision of special services (at your initiative as well as theirs) to many divergent groups on and off campus, even though that places new demands on the library. It certainly means working with the deans and department chairs and development officers to ensure that they, too, consider part of their responsibility in raising funds for new programs and lab resources, is to consider the cost of library services and resources. If you are visible, you will have a better chance in placing the library as a priority on campus, even when resources are limited and everyone is competing for limited funds. But, you also have to prove your effectiveness and ability to balance many needs.

To justify your need, you must:

1. Keep users informed about collections and services-strengths and weaknesses.

2. Demystify libraries and make them userfriendly.

3. Be an active fundraiser to demonstrate commitment.

4. Provide enhanced/improved services, new services, and eliminate the no longer viable.

5. Provide a positive approach to service.
6. Have the expertise in operations and service and willingness to add new services to meet demands.

7. Demonstrate popular support from groups both on and off campus.

\section{Proposals for PR}

In establishing effective PR, the library must provide services that are seen in a positive lightthat requires self-motivated personnel, expertise in a variety of functions, management abilities on the part of each staff member, and willingness to reduce and eliminate wasted efforts or little-used services in order to enhance and improve others and develop new ones. Proposals should be carefully thought out and include a brief summary of the purpose, impact on current operations and services, assets/liabilities, methodologies and resources needed for implementation, a trial project period, method of evaluation, and all associated costs, including committee time, individual staff time, and internal/external costs for supplies, equipment, clerical support, etc. The proposal should also include what groups (within and outside of the libraries), if any, should be asked to provide input and critique potential benefits and possible problems prior to implementation and during the evaluation period.

\section{Development of PR Plans}

Many libraries undertake user surveys or marketing studies prior to developing a $\mathrm{PR}$ plan. $\mathrm{Al}-$ though such can be advantageous in determining needs and assessing desires, there is some danger in doing this if you are not a specialist in developing questionnaires. You may also find that by asking users what they want, you have raised expectations that you cannot meet and demands for services that are useful only to a very limited population.

I would suggest that, prior to conducting a market analysis of needs, the library first draft a mission statement defining purpose and role of the library, client groups to be served, and the relation of the library to the parent institution and any outside constituencies served by the institution. This statement should also include broad goals and specific objectives (with who is to accomplish what, what resources will be needed, and possible sources of funding - along with a deadline for completion to assess a short- or long-range need). Priorities should be determined for every objective. This should be reviewed with the administration, deans, the faculty senate library committee, the Friends of the Libraries, and any other appropriate group, so as to gain approval for overall concepts and priorities. This should be followed by a broad narrative overview (brief and concise), a case-statement, 
which clarifies the library's primary role and clientele, key goals, the library's accomplishments, and resources needed in meeting the needs of clientele. This should be followed by a listing of specific needs by category with anticipated cost of each, in priority order.

This case statement can later be further refined, into smaller one to two page proposals of special services, collections, program needs for funding requests to special groups, corporations, granting agencies, foundations, or individual donors.

PR programs are costly - especially in terms of planning, staff or committee review and further refinement of time, resources needed for implementation and evaluation. Thus, support must be widespread and a focus clearly defined so that staff to carry out the projects are not overwhelmed with programs of little value, or those that take too much staff time.

Every step of the process will require close working relationships with library staff, university administration and development officers, as well as with other advisory and governance bodies inside and outside of the University. This is imperative to ensure widespread support and a clear understanding of where the planned fundraising or service priorities fit within the overall institutional planning.

\section{Costs, benefits, and financial implications}

It would be an ideal situation if libraries did not have to sell themselves, if the parent institution, public support and tax dollars, and private sector funding would be adequate. However, that usually isn't the case. And in the recent past public institutions have had to spend much more time competing with private institutions for private-sector funding. PR and promotional programs are multi-faceted. Some are focused on fundraising; others on providing basic, expanded, or new services. Before we get larger allotments, or even the same base-line support as in previous years, we are expected to help ourselves, to prove our worth. PR programs can help with this.

Most of us seem to be doing more fundraising for libraries. Unless additional development staff can be hired to carry out these new or raised expectations, most academic libraries are forced to rethink how staff time can be reallocated and PR adjusted to include a focus on fundraising efforts, without detrimental effects on our users. This means revising priorities, redefining time devoted to traditional services, and targeting all services and PR activities to ensure we have broad-based support and a positive public image in all operations and services provided. Demand for traditional services grows as universities refocus on educational reform. And new services are demanded as technolo- gies grow and develop, even while many old services cannot be dismantled because they are still necessary. How do we meet all these obligations? We cost out all services, determine priorities, and reduce and eliminate what we can in order to add the new. And we look at everything in terms of its value to existing primary clientele, how it might help build supplementary income, as well as whether it will attract potential new clientele and a new donor pool.

The costs of an effective PR campaign can be divided into monetary and non-monetary. If we do not put staff time and energy into the planning and advocacy roles, we lose out in fiscal terms and in a potential negative image. An effective campaign is costly in terms of staff time, scarce resources, and risk-taking. It takes money to make money for developing libraries and library services-so we must cut corners, reallocate institutional support funds, in order to find ways to do a better job and to bring in more dollars. In order to do this effectively, we have to focus our energies, determine which operations, services, and programs are priorities for both short-term and long-term benefits. And, sometimes the immediate needs are going to suffer in exchange for a potential long-term development. We cannot, for example, establish a business information service that will pay for itself initially unless we cut something else. Or staff may be asked to reduce reference hours or cataloging productivity in order to complete a grant request, or instructional handouts for students might have to be reduced in order to find more time to develop stronger faculty ties.

Everything has a negative side, cutting out a service that a few or many may cherish to meet a new user group need, a potential major donor's expectations, or to provide a new reference service may cause loss of support. We may lose support of traditional users in order to gain stronger support from those who are in a position to provide monetary and other support down the road. The positive side may mean a broader-based support, a stronger, more positive public image, an improved relationship and stature with faculty as equal partners in the educational exchange. It may mean greater visibility and enhanced credibility. Regardless of our feelings about whether a new project or fundraising is a detriment or an enhancement, the expectation for increased emphasis on this role is there. Our task is to assume new responsibilities as effectively as we can. That means a focused PR program - too many PR projects and add-on tasks will create splintering, resentments, and loss of support. Planning is vital.

It helps to have an advancement officer whose time (full-time) can be used to work on public relations and fundraising activities. This type of position is becoming much more popular in the 
larger academic libraries and, even in the frequently smaller private-institution academic libraries. Often these individuals do not have a library degree but rather, come from the accounting or marketing segment of the population.

There are two major divisions for public relations in academic libraries-internal and external. The internal PR activities are often focused on:

1. Displays and exhibits.

2. News items, press releases in campus publications, and newsletters and acquisitions lists.

3. Library user education programs, with a secondary purpose of compilation of instructional guides and handouts, or media type and CAI programs.

4. Suggestion boxes, question/response boards.

5 . Receptions honoring students and faculty.

6. Book sales of surplus, gift, and discarded books (often coordinated with the campus bookstore).

The external PR activities, often less coordinated, may include:

1. Friends meetings, lectures, and receptions.

2. Friends publications and newsletters.

3. Guest lecturers for Friends' groups.

4. Press releases for local news media.

5. Special project fund-raising efforts utilizing
Friends volunteers and community leaders-e.g. fine book auctions, auctions of community services, building fund campaigns-major capital campaigns and special dinners and mail solicitations, etc.

In many libraries, the external public relations activities are primarily tied to the manuscript, archives, special collections, or rare books sections and Friends groups. However, this is changing as university officials are relying more and more on outside fundraising support to keep universities afloat, not just as supplemental or enrichment funds.

An aggressive $P R$ program should be one of the top priorities of any library-and, even though it helps to have one or two top-level library administrators devote an extensive percentage of their time to plan, administer, and coordinate PR activities, it is a job that should be considered part of every single staff member's position description. Each should know their own role and assume it. Recruiting and motivating library personnel to be creative, innovative, risk-takers, and potential fundraisers is the key.

There has to be more than one PR person in the library. Every staff member should be a PR activist for the library.

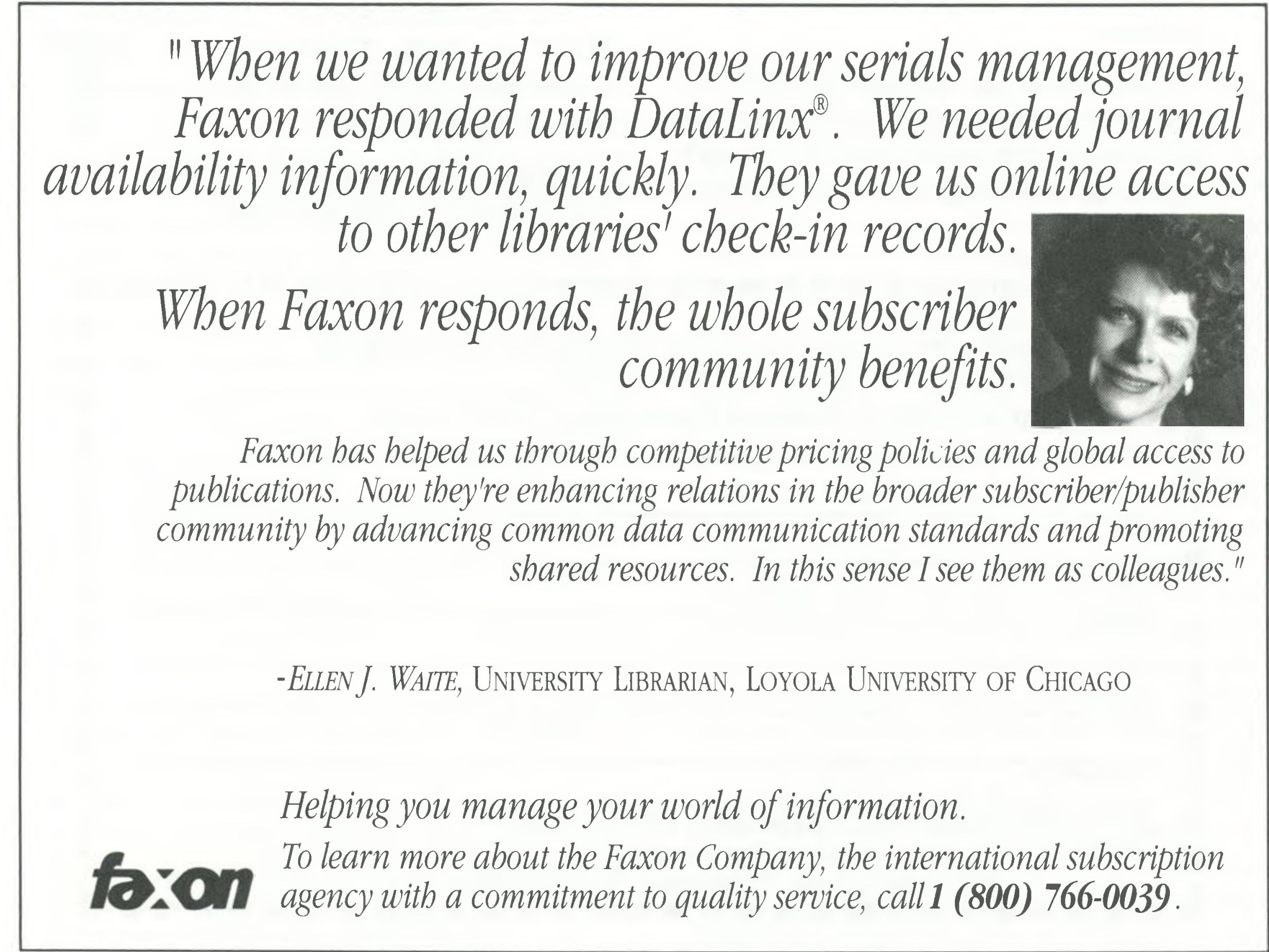




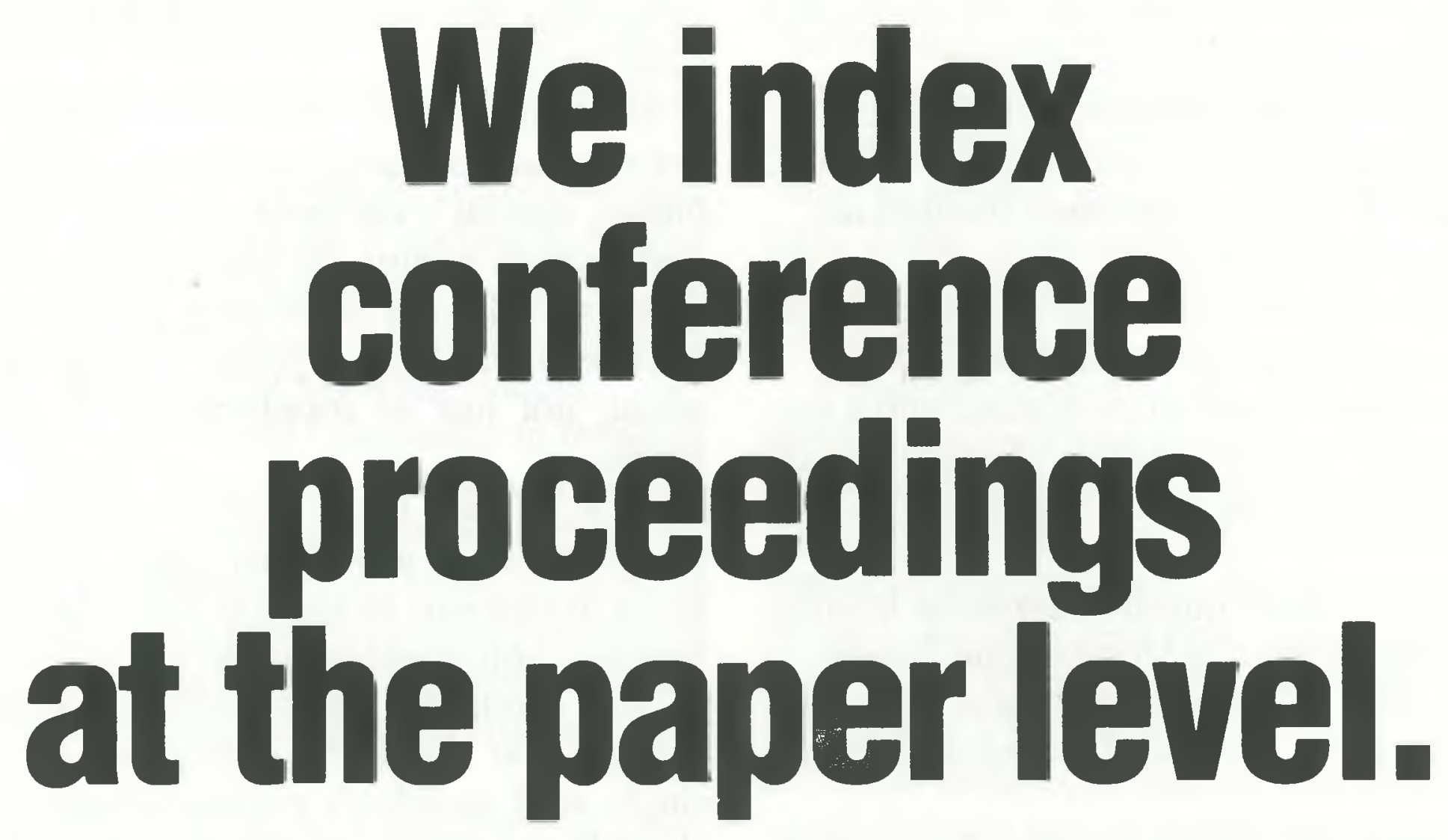

When you're searching for a specific proceedings paper, turn to the only two sources where you can find it fast...the Index to Scientific \& Technical Proceedings $^{\circledast}$ and the Index to Social Sciences \& Humanities Proceedings ${ }^{(*)}$.

Current and comprehensive coverage. ISTP ${ }^{\circledR}$ and $I S S H P^{\circledast}$ provide access to thousands of proceedings papers titles-from nearly 100 key disciplines.

Information is indexed in ISTP and ISSHP as soon as it's published in the conference proceedings literature...up to a year before it appears in any journal or other index.
Easy access. You can quickly locate information on specific papers with any one of six access points:

- category - meeting location - sponsor author/editor $\cdot$ subject $\cdot$ author address

FREE issues. See for yourself. Order a free ISTP monthly issue or ISSHP quarterly issue or both...today. Just complete the coupon below.

For immediate service, call Operator R347 at (800) 336-4474 (U.S. and Canada) or (215) 386-0100, extension 1483 (elsewhere).

Search ISTP and ISSHP-first-for the research results you need.

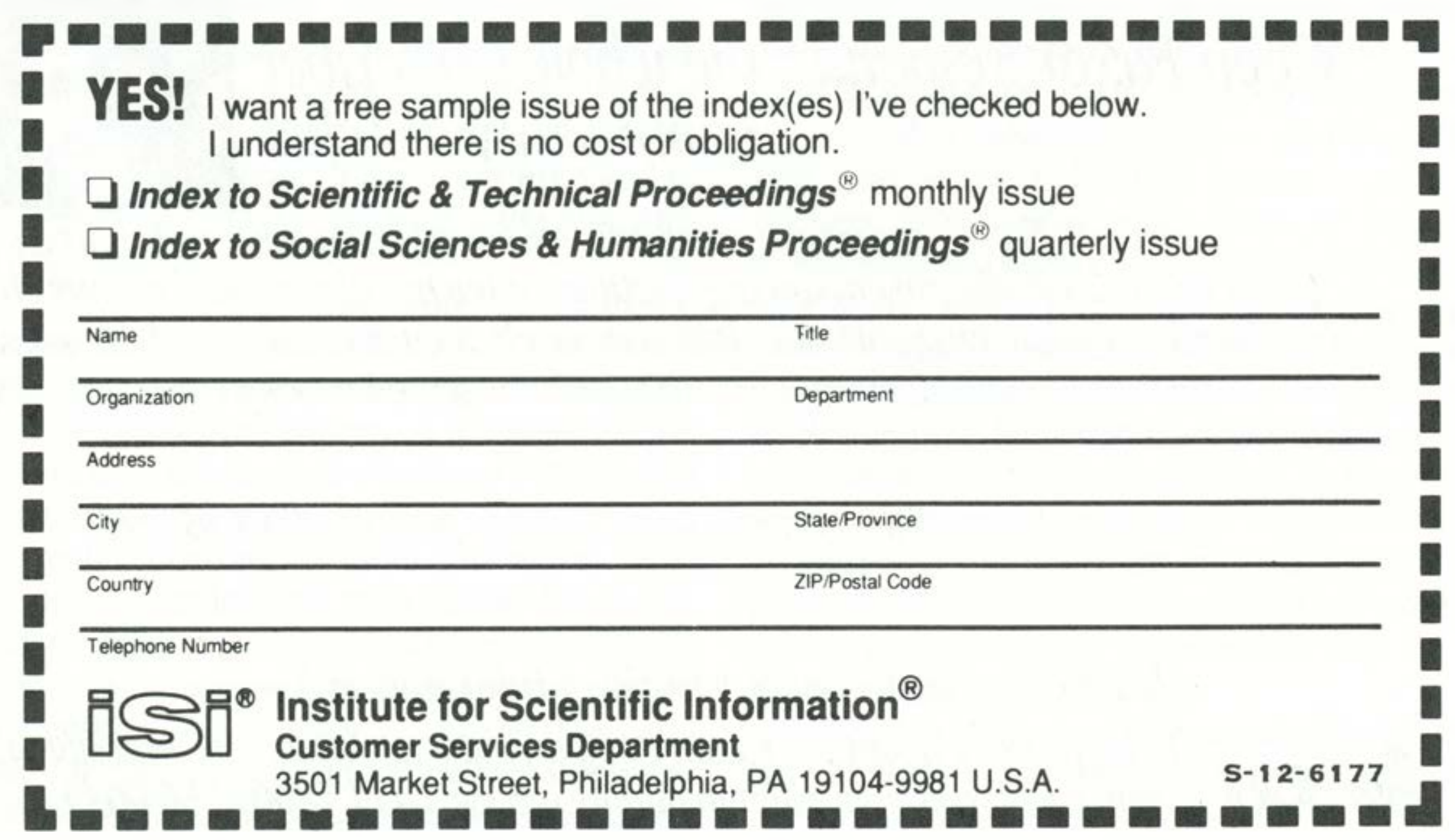

